\title{
A CITRICULTURA ORGÂNICA NA REGIÃO DO VALE DO CAÍ (RS): RACIONALIDADE SUBSTANTIVA OU INSTRUMENTAL?
}

\section{THE ORGANIC TANGERINE IN “VALE DO CAÍ" (RS): SUBSTANTIVE OR INSTRUMENTAL RATIONALITY?}

\section{LESSANDRA SCHERER SEVERO}

Mestre em Gestão da Tecnologia e Produção pela Escola de Administração da Universidade Federal do Rio Grande do Sul (PPGA-UFRGS).

Rua 3.750, 75, ap. 901, Edifício Oliveira, Centro Balneário Camboriú - SC - CEP 88330-194 E-mail: scherersevero@yahoo.com.br

\section{EUGÊNIO ÁVILA PEDRozo}

Doutor pelo Institut National Polytechnique de Lorraine (França). Professor de pós-graduação na Escola de Administração da Universidade Federal do Rio Grande do Sul (PPGA-UFRGS). Rua Washington Luís, 855, Cidade Baixa - Porto Alegre - RS - CEP 90010-460 


\section{RESUMO}

Com base na premissa de que a tomada de decisão é um processo lógico, fruto da inteligência e racionalidade humana, objetiva-se com esse trabalho verificar se os agricultores orgânicos cooperados da Ecocitrus, ao decidirem pelo cultivo orgânico, estavam mais inclinados a uma motivação substantiva ou instrumental e, por conseguinte, se a cooperativa pode ser considerada hoje uma organização substantiva ou não. Este artigo baseou-se no modelo de aplicação teórica sobre racionalidade de Mauricio Serva (1993, I997) e na proposta de organizações substantivas de Guerreiro Ramos (1989). O método utilizado é essencialmente qualitativo, com caráter exploratório-descritivo. Os sujeitos da pesquisa são produtores de bergamota orgânica, cooperados da Ecocitrus. Os dados foram levantados em julho e agosto de 2005 , por meio de entrevistas semi-estruturadas e aplicação de questionários fechados. Por fim, os resultados permitiram caracterizar a Ecocitrus como uma organização substantiva de intensidade elevada.

\section{PALAVRAS-CHAVE}

Citricultura orgânica; Racionalidade instrumental; Racionalidade substantiva; Organização substantiva; Cooperativa.

\section{ABSTRACT}

Considering the decision process as a logical process, resulted form human intelligence and rationality, the proposal of this paper is to verify if the organic agriculturists were more inclined to a substantive or instrumental rationality and if their Cooperative Ecocitrus can be classified as a substantive organization. This paper was based on the theoretical model about rationality constructed by Mauricio Serva (1993, 1997) and on the proposal of substantive organizations by Guerreiro Ramos (I989). It is a theoretical-empiricist study with qualitative approach and posing a descriptive and exploratory character. Taking in account some results, came 
by semi-structured interview and by closed questionnaires, applied in July and August 2006, it was possible characterize Ecocitrus as a high intensity substantive organization.

\section{KEYWORDS}

Organic tangerines; Instrumental rationality; Substantive rationality; Substantive organization; Cooperative.

\section{INTRODUÇÃO}

Percebe-se no atual contexto uma crescente procura por parte dos consumidores por alimentos seguros e mais saudáveis, como os produtos orgânicos. Nas grandes capitais, já é possível encontrar, em alguns supermercados, verduras, legumes e frutas cultivadas sem o uso de agrotóxicos, além de feiras e mercados alternativos que comercializam semanalmente uma variedade de alimentos orgânicos e integrais.

Mais expressivo ainda se mostra o crescimento desses produtos pelo mercado externo. Segundo França et al. (2002), café, suco de laranja, soja, açúcar mascavo, erva-mate, cacau, óleo de dendê, frutas secas, castanha de caju e guaraná estão entre os produtos exportados com essa característica. Os autores afirmam ainda que essas exportações representam anualmente cerca de US\$ Ioo milhões.

O principal problema encontrado pelos produtores que buscam a conversão de suas cullturas para o sistema orgânico é não só o modelo tecnológico, mas também a mudança de percepção. O produtor acostumado a perceber a tecnologia da química agrícola como meio de aumentar a qualidade, produtividade e rentabilidade de seus cultivos deve, na prática orgânica, acreditar exatamente no inverso e compreender esse processo.

Na verdade, o que a prática de cultivos orgânicos propõe é uma retomada de antigos procedimentos que deverão ser atrelados a tecnologias recentes. Até meados do século XIX, as terras exploradas pela agricultura tinham sua produtividade recuperada de duas formas: pousio e adubação orgânica, com excrementos de animais (KHATOUNIAN, 200I). Foi em meados do século XIX, como resultado dos estudos de Saussure (I797-I845), Boussingault (I802I887) e Liebig (I803-I873), que se passou a utilizar elementos químicos para recuperação dos solos.

Khatounian (200I) esclarece que na própria Alemanha, berço da química agrícola, surgiram as primeiras escolas que retomaram as práticas desprovidas 
de elementos químicos. Foi a escola da biodinâmica, tida como a mais antiga escola de agricultura orgânica, portanto a primeira a questionar os indesejáveis efeitos da química agrícola.

Em suma, a agricultura convencional ou agroquímica é caracterizada pela exploração intensiva da terra (normalmente monoculturas) e pelo uso (freqüentemente desmedido) de fertilizantes (químicos, sintéticos), herbicidas, pesticidas e agrotóxicos, da energia fóssil e nuclear, da petroquímica e da engenharia genética. Ela tem sido apontada como responsável por problemas ambientais, como erosões do solo, contaminação de lençóis aqüíferos, rios, lagos e alimentos e diminuição da biodiversidade de espécies, e por problemas sociais, como a dependência do produtor ante a indústria química, genética e de equipamentos agrícolas.

Por sua vez, as culturas alternativas (biodinâmica, permacultura, agroecologia, orgânicos, biológica, natural, alternativa, ecológica...) caracterizam-se pela não-utilização de defensivos ou fertilizantes químicos e pelo uso racional e medido do solo e demais recursos naturais. Como mencionado, essas práticas têm crescido consideravelmente na última década, como conseqüência de uma maior conscientização de grupos de consumidores que, cada vez mais, se preocupam com a segurança daquilo que consomem, buscando alimentos certificados, como os orgânicos.

O produto orgânico é visto também como resultado de um sistema de produção agrícola sustentável, que trabalha as lavouras respeitando os limites do meio ambiente e buscando um equilíbrio deste com as necessidades sociais e econômicas. Portanto, os agricultores orgânicos, ao contrário dos convencionais, confiam no solo sadio, na observação cuidadosa e nos níveis controláveis de pragas para aumentar suas colheitas. Na visão orgânica, baseada no ecossistema, a erradicação total das pestes é um erro tático, pois o sistema salutar precisa de certa quantidade de pragas que sirvam de alimento aos predadores para que eles fiquem por perto e as conservem em equilíbrio (HAWKEN et al., I999, p. I83).

Czapski (2005), com base em dados do Ministério da Agricultura, Pecuária e Abastecimento (Mapa), apresenta o Brasil como vice-campeão mundial em área de produção orgânica, com 6,5 milhões de hectares, estando à sua frente apenas a Austrália. Em 2003, o país ocupava o 34ffl posto do ranking, com pouco mais de 8Io mil hectares. Segundo a autora, o motivo do salto foi a decisão de incluir 5,7 milhões de hectares do extrativismo sustentável, onde há açaí, látex e outros produtos da floresta; tal decisão resultou em maior visibilidade para a agroecologia.

O sistema de cultivo orgânico e os produtos orgânicos foram normatizados pelo Mapa por meio da Instrução Normativa nffl o07/99, e sua abrangência engloba todos os sistemas de culturas alternativas supracitados. No geral, essa normativa estabelece as normas para os produtos orgânicos de origem vegetal 
e animal quanto a produção, tipificação, processamento, envasamento, distribuição, identificação e certificação da qualidade. No Brasil, os órgãos colegiados em âmbito nacional e estadual são os responsáveis pelo credenciamento das instituições de certificação e controle da qualidade dos produtos orgânicos (KNY et al., 2005).

Com base no contexto apresentado e considerando a tomada de decisão um processo lógico, fruto da inteligência e racionalidade humana, traçou-se o seguinte objetivo: verificar se os agricultores orgânicos cooperados da Ecocitrus, ao optarem pelo sistema orgânico de cultivo, estavam mais inclinados a uma motivação substantiva ou instrumental e, com isso, se a cooperativa pode ser considerada hoje uma organização substantiva ou não. Nas próximas seções, realizam-se a discussão acerca da racionalidade, a contextualização da citricultura e a descrição da Cooperativa Ecocitrus, representante dos produtores orgânicos. Em seguida, analisam-se os resultados coletados.

\section{RACIONALIDADE}

Vivemos numa sociedade em que as relações dão-se, na sua maioria, com base em cálculos utilitários, em avaliações de custo e benefício. Nesse contexto, o mercado é o principal, quando não único, orientador de decisões organizacionais e individuais. Sem incluir, muitas vezes, outro tipo de critério de avaliação nos processos de decisão de ações, a sociedade tem seus princípios orientados por essa racionalidade utilitarista. De tal forma, cresce a discussão sobre a predominância da razão instrumental (funcional) que orienta as decisões dos homens ante diferentes situações.

Por razão entende-se a capacidade do ser humano de avaliar, julgar, compreender, raciocinar, ponderar idéias e estabelecer relações lógicas. A palavra razão vem do latim ratione, que significa raciocinar, inteligência. Em seu livro Ciência com consciência, Edgar Morin (2002) realiza uma importante distinção entre razão, racionalidade e racionalismo. A primeira consiste no método de conhecimento baseado no cálculo e na lógica. Racionalidade é a adequação entre coerência lógica e realidade empírica, enquanto racionalização é a construção de uma visão coerente e completa do universo, a partir das partes ou do princípio único.

Assim, racionalidade, do latim rationalitate, é a qualidade de raciocinar, ou seja, de fazer uso dessa razão para: "conhecer, julgar e elaborar pensamentos e explicações e é ela que habilita o homem a escolher entre alternativas, a julgar os riscos decorrentes das suas conseqüências e efetuar escolhas conscientes e 
deliberadas" (PEREIRA; FONSECA, I997, p. I77). Guerreiro Ramos (I989), principal teórico da racionalidade nas organizações, apresenta a razão como conceito básico de qualquer ciência da sociedade e das organizações, e adverte que a sociedade moderna adotou a racionalidade funcional como orientadora das ciências sociais e da vida humana em geral, e sua influência ilimitada sobre a vida humana prejudica suas qualificações éticas.

Weber (2004), em Economia e sociedade, desenvolveu o conceito de ação social como o comportamento humano que é orientado por uma conduta de outra pessoa ou grupo, sendo os valores e fins contidos no ambiente e no próprio homem fatores limitantes dessa ação. Para melhor classificação e compreensão do que pretendia dizer por ação social, Weber desenvolveu os tipos ideais de ações, dividindo os aspectos envolvidos no comportamento humano em irracionais, ou afetivamente condicionados, e racionais, ou em relação aos fins.

Assim, para Weber são quatro os tipos ideais de ação social: afetiva (movida por sentimentos), tradicional (movida por hábitos), racional com relação a um valor (movida pela crença consciente num valor, por uma convicção) e racional com relação a um objetivo (movida pelo cálculo racional dos fins e dos meios). Weber apresenta esses tipos de ação como ideais ou puros, ou seja, raramente serão encontradas na realidade ações puramente afetivas ou de qualquer outro tipo, e sim uma mescla desses tipos, com a prevalência de um deles. São os tipos ideais de Weber construídos de forma a definir um conceito prévio, com o propósito de facilitar a análise de questões empíricas.

Nessa discussão, Weber acrescenta os tipos de racionalidades: prática, teorética, substantiva e formal. Nas racionalidades prática e formal, a ação é racional com relação a um objetivo, ou seja, o julgamento dá-se com base em interesses individuais ou organizacionais, práticos e egoístas. Na racionalidade substantiva, a orientação para a ação humana está baseada em valores, independentemente dos resultados a serem obtidos. Na racionalidade teorética, de caráter teórico, percebe-se a realidade com a construção de conceitos abstratos mais do que por suas ações. Correia e Dorneles (2003), ao tratarem da relação criatividade e racionalidade, afirmaram que os tipos de racionalidades não estão diretamente ligados aos de ação social, uma vez que as ações tradicionais e afetivas não são ações racionais e sim irracionais.

Na busca de uma definição de ação administrativa, Guerreiro Ramos (1983) remete-se à discussão de ação social de Weber (2004) e, em seguida, aos tipos de racionalidade. Nessa discussão, Ramos também cita as suposições levantadas por Chester Barnard (I97I) quanto à racionalidade do indivíduo no seu aspecto individual e como participante de um sistema cooperativo. Com isso, Ramos (I983) discute os tipos de racionalidade que motivam a ação do homem e, por conseguinte, do administrador. 
Simon (1997) também participou dessa discussão e descreveu seis tipos de racionalidade que moveriam o comportamento dos gestores de uma organização. Esses tipos se limitam ao ambiente e ao próprio tomador de decisão, que não tem como dispor de todo o conhecimento a respeito de uma situação determinada. Os seis tipos de racionalidade de Simon são: a) objetiva: baseada em dados mensuráveis; b) subjetiva: baseada em dados visíveis, orientados por valores e experiências; c) consciente: quando ocorre uma adequação dos meios aos fins propositalmente; d) deliberada: quando a adequação dos meios aos fins é deliberadamente provocada; e) pessoal: que atende a objetivos individuais; f) organizacional: que atende a objetivos organizacionais.

Anos mais tarde, Guerreiro Ramos (1989), crítico das bases essencialmente instrumentais com as quais constituiu a ciência da administração, propõe em seu livro A nova ciência das organizações o conceito de organização substantiva. Por considerar as distinções de Simon insatisfatórias, Ramos trabalhou com dois tipos de racionalidade, partindo da distinção que Max Weber fez entre os conceitos de Wertrationalität (racionalidade substantiva, ou de valor) e Zweckrationalität (racionalidade formal ou funcional). Ramos (I989, p. 29) apresenta esses dois tipos de racionalidade em relação à teoria da vida humana associada, no entanto o autor foca sua análise na racionalidade substantiva como categoria básica. Outro fator determinante das análises do autor é a disciplina da ética, considerando esta em dois níveis: a ética da responsabilidade corresponde à ação racional referida a fins e a ética do valor absoluto ou de convicção, implícita em toda a ação referida a valores.

Os estudos de Guereiro Ramos foram significativamente influenciados por Mannheim (I973), que, ao estudar a racionalidade, recorreu aos adjetivos "funcional" e "substancial". Mannheim observou que a industrialização favorecia a racionalidade funcional, submetendo o homem a critérios funcionais, antes que substanciais, de entendimento e compreensão. Outra conseqüência da "funcionalização" da racionalidade humana levantada pelo autor é a questão de concentração de renda, que restringe a relativamente poucos a propriedade dos meios de produção e o poder de decidir e organizar (RAMOS, I989, p. 40).

Assim, a racionalidade instrumental (ou funcional) orienta a conduta humana como um meio para atingir determinado fim, ou seja, a ação é estimulada por uma estimativa utilitária das conseqüências. Na racionalidade funcional, não se aprecia propriamente a qualidade intrínseca das ações, mas o seu maior ou menor concurso, numa série de outros, para atingir um fim preestabelecido, independentemente do conteúdo que possam ter as ações (RAMOS, I983, p. 39).

Por sua vez, a racionalidade substantiva é inerente ao homem, sendo o seu lugar adequado a psique humana. Portanto, toda ação orientada por uma razão substantiva baseia-se num conhecimento lúcido e autônomo de relações entre 
fatos, atestando o ser humano como criatura dotada de razão. Conseqüentemente, a razão preside um ato de domínio de impulsos, sentimentos, emoções, preconceitos e de outros fatores que perturbam a visão e o entendimento inteligente da realidade, e está estreitamente relacionada com a preocupação em resguardar a liberdade (RAMOS, I983, p. 39).

Sumariamente, a razão substantiva diz respeito a julgamentos, avaliações com base em preceitos (valores) morais e éticos, enquanto a instrumental referese a julgamentos baseados em critérios meramente utilitários, funcionais.

Por fim, o conceito de organização substantiva proposto por Ramos (1989) trata de uma organização cujas ações são orientadas essencialmente pela racionalidade substantiva. Trata-se de uma organização que, assim como os tipos ideais de Weber, não é encontrada na realidade de forma pura, como também não existem organizações puramente instrumentais. Esse tipo de organização preocupase com a redução e eliminação de compulsões desnecessárias sobre as atividades humanas, de descontentamentos e alienação.

Ramos (I989, p. I36) apresenta cinco diretrizes que devem ser consideradas na construção da abordagem da organização substantiva:

- O homem tem diferentes necessidades, que devem ser atendidas por múltiplos cenários sociais.

- O sistema de mercado só satisfaz algumas dessas necessidade humanas, determinadas por um cenário social específico fortemente influenciado por critérios intencionais e instrumentais, condicionando a conduta humana a imperativos econômicos.

- A categoria de tempo e espaço dos cenários econômicos é apenas um caso particular a ser considerado entre outros.

- Diferentes sistemas cognitivos pertencem a diferentes cenários organizacionais, portanto as regras cognitivas referentes ao comportamento administrativo também constituem caso particular.

- Diferentes cenários sociais requerem enclaves distintos no contexto geral da sociedade, embora haja inter-relações entre eles.

Mauricio Serva (1993, 1997) buscou, em seus trabalhos acerca do assunto, dar continuidade à proposta de Guerreiro Ramos, aplicando-a empiricamente. Para Serva (1997), nas organizações substantivas há, predominantemente, em seus processos administrativos e organizacionais, a racionalidade substantiva. Nessas organizações, existe o ideal da emancipação do ser humano e do resgate da condição humana no âmbito do trabalho, e suas atividades são marcadas por valores como autenticidade, respeito a individualidade, dignidade, solidariedade e afetividade. 
Para Serva (I997), os elementos constitutivos da ação racional substantiva no interior da organização são: auto-realização, entendimento, julgamento ético, autenticidade, valores emancipatórios e autonomia. Por sua vez, elementos como cálculo, preocupação com os fins, com a maximização dos recursos, êxito, resultados e desempenho, utilidade, rentabilidade e estratégia interpessoal caracterizam a ação racional instrumental. Com isso, o autor criou um continuum da intensidade da racionalidade substantiva, sendo sua análise contrária à representação da racionalidade instrumental. É com base nesse continuum constituído por Mauricio Serva que decorrerá este estudo.

\section{FIGURA I}

CONTINUUM DE INTENSIDADE

DE RACIONALIDADE SUBSTANTIVA

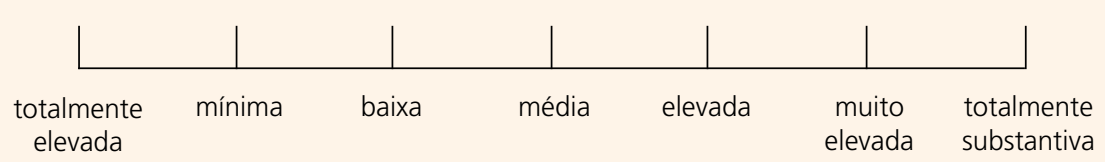

Fonte: Serva (1997, p. 25).

A proposta de Serva (1997) permite, por meio da identificação de fatores como características da organização e divisão do trabalho, estrutura e cultura organizacional e características pessoais, verificar a existência ou não de elementos da ação racional substantiva ou da instrumental. São elementos como: cálculo, fins, maximização dos recursos, êxito, resultados, desempenho, auto-realização, entendimento, julgamento ético, autenticidade, valores emancipatórios, autonomia em cada um dos processos organizacionais estudados.

Serva (1997) descreveu as características dos elementos que compõem a ação racional substantiva e instrumental. Na ação racional substantiva, observam-se: a) auto-realização: processos de concretização do potencial inato do indivíduo, complementados pela satisfação; b) entendimento: ações pelas quais se estabelecem acordos e consensos racionais, mediados pela comunicação livre, e que coordenam atividades comuns sob a égide da responsabilidade e satisfação sociais; c) julgamento ético: deliberação baseada em juízo de valor (bom, mal, verdadeiro, falso...), que se processa pelo debate racional sobre as pretensões de validez emitidas pelos indivíduos nas interações; d) autenticidade: integridade, honestidade e franqueza dos indivíduos nas interações; e) valores emancipatórios: aqui se destacam os valores de mudança e aperfeiçoamento do social nas direções do bemestar coletivo, da solidariedade, do respeito à individualidade, da liberdade e do 
comprometimento, presentes nos indivíduos e no contexto normativo do grupo; f) autonomia: condição plena para que os indivíduos possam agir e expressar-se livremente nas interações.

Na ação racional instrumental, há: a) cálculo: projeção utilitária das conseqüências dos atos humanos; b) fins: metas de natureza técnica, econômica ou política; c) maximização dos recursos: busca pela eficiência e eficácia máximas, sem questionamento ético, no tratamento de recursos disponíveis, humanos, materiais, financeiros, técnicos, energéticos ou de tempo; d) êxito, resultados: o alcance, em si mesmo, de padrões, níveis, estágios, situações que são considerados vitoriosos, ante processos competitivos numa sociedade capitalista; e) desempenho: performance individual elevada na realização de atividades, centrada na utilidade; f) utilidade: dimensão econômica considerada na base das interações como um valor generalizado; g) rentabilidade: medida de retorno econômico, dos êxitos e dos resultados esperados; h) estratégia interpessoal: aqui entendida como influência planejada sobre outrem, a partir da antecipação das reações prováveis desse outrem a determinados estímulos e ações, visando atingir seus pontos fracos.

O Quadro I, construído por Serva (1997), resume a descrição de alguns processos organizacionais relacionados com os elementos da racionalidade já descritos. Deve-se lembrar que uma ação, decisão, humana não é necessária e totalmente instrumental ou substantiva, pelo contrário, ela pode ser influenciada por diferentes fatores às vezes mais substantivos, outras vezes mais instrumentais. Serva (1997, p. 23) afirma que sua suposição conceitual tem por fundamento a idéia de que a dinâmica do cotidiano das organizações produtivas implica a presença tanto da razão substantiva quanto da instrumental.

QUADRO I

ANALISE DOS PROCESSOS ORGANIZACIONAIS

E ELEMENTOS DE RACIONALIDADE

\begin{tabular}{ccc}
\hline $\begin{array}{c}\text { TIPO DE RACIONALIDADE } \\
\text { VERSUS } \\
\text { PROCESSOS ORGANIZACIONAIS }\end{array}$ & $\begin{array}{c}\text { RACIONALIDADE } \\
\text { SUBSTANTIVA }\end{array}$ & $\begin{array}{c}\text { RACIONALIDADE } \\
\text { INSTRUMENTAL }\end{array}$ \\
\hline Hierarquia e normas & $\begin{array}{c}\text { Entendimento } \\
\text { e julgamento ético }\end{array}$ & $\begin{array}{c}\text { Fins, desempenho e } \\
\text { estratégia interpessoal }\end{array}$ \\
Valores e objetivos & $\begin{array}{c}\text { Auto-realização, } \\
\text { valores emancipatórios e } \\
\text { julgamento ético }\end{array}$ & $\begin{array}{c}\text { Utilidade, } \\
\text { fins e } \\
\text { rentabilidade }\end{array}$ \\
\hline
\end{tabular}




\section{QUADRO I (CONCLUSÃO)}

ANALISE DOS PROCESSOS ORGANIZACIONAIS E ELEMENTOS DE RACIONALIDADE

\begin{tabular}{|c|c|c|}
\hline $\begin{array}{c}\text { TIPO DE RACIONALIDADE } \\
\text { VERSUS } \\
\text { PROCESSOS ORGANIZACIONAIS }\end{array}$ & $\begin{array}{l}\text { RACIONALIDADE } \\
\text { SUBSTANTIVA }\end{array}$ & $\begin{array}{l}\text { RACIONALIDADE } \\
\text { INSTRUMENTAL }\end{array}$ \\
\hline Tomada de decisão & $\begin{array}{l}\text { Entendimento e } \\
\text { julgamento ético }\end{array}$ & $\begin{array}{c}\text { Cálculo, utilidade e } \\
\text { maximização de recursos }\end{array}$ \\
\hline Controle & Entendimento & $\begin{array}{c}\text { Maximização de recursos, } \\
\text { desempenho e } \\
\text { estratégia interpessoal }\end{array}$ \\
\hline Divisão do trabalho & $\begin{array}{c}\text { Auto-realização, } \\
\text { entendimento e autonomia }\end{array}$ & $\begin{array}{c}\text { Maximização de recursos, } \\
\text { desempenho e cálculo }\end{array}$ \\
\hline $\begin{array}{c}\text { Comunicação e relações } \\
\text { interpessoais }\end{array}$ & $\begin{array}{c}\text { Autenticidade, valores } \\
\text { emancipatórios e autonomia }\end{array}$ & $\begin{array}{l}\text { Desempenho, êxito/ } \\
\text { resultados e estratégia } \\
\text { interpessoal }\end{array}$ \\
\hline $\begin{array}{c}\text { Ação social e relações } \\
\text { ambientais }\end{array}$ & Valores emancipatórios & Fins e êxito/resultados \\
\hline $\begin{array}{l}\text { Reflexão sobre } \\
\text { a organização }\end{array}$ & $\begin{array}{c}\text { Julgamento ético e valores } \\
\text { emancipatórios }\end{array}$ & $\begin{array}{l}\text { Desempenho, fins e } \\
\text { rentabilidade }\end{array}$ \\
\hline Conflitos & $\begin{array}{l}\text { Julgamento ético, autenticidade e } \\
\text { autonomia }\end{array}$ & $\begin{array}{c}\text { Cálculo, fins e estratégia } \\
\text { interpessoal }\end{array}$ \\
\hline Satisfação individual & Auto-realização e autonomia & Fins, êxito e desempenho \\
\hline Dimensão simbólica & $\begin{array}{c}\text { Auto-realização e valores } \\
\text { emancipatórios }\end{array}$ & $\begin{array}{c}\text { Utilidade, êxito/resultados } \\
\text { e desempenho }\end{array}$ \\
\hline
\end{tabular}

Fonte: Serva (I997, p. 24).

\section{CONTEXTUALIZAÇÃO DA CITRICULTURA}

O agronegócio, ou agribusiness, como definido por Davis e Goldberg (I957), trata do conjunto de atividades envolvidas no processamento e na distribuição dos insumos agropecuários, nas operações de produção na fazenda, no armazenamento, no processamento e na distribuição dos produtos agrícolas e seus derivados, ou seja, da produção de insumos à venda do produto ao consumidor 
final. É um dos principais setores da economia brasileira e responsável por cerca de um terço do produto interno bruto (PIB) do país em 2004, registrando uma taxa de crescimento em torno de $5 \%$ ao ano (CEPEA/ESALQ/USP). Tamanha é a importância do setor ao país que, do total do território utilizado em 2002, cerca de 852 milhões de hectares, mais de $30 \%$ eram utilizados para a agricultura (FOOD AND AGRICULTURE ORGANIZATION..., 2005).

O agronegócio da fruticultura tem significativa importância mundialmente, dada a sua representatividade de produção e movimentação financeira e, também, tendo em vista a sua importância na alimentação humana. No Brasil, a fruticultura ocupa uma área de dois milhões de hectares comerciais e gera um PIB de US\$ I,5 bilhão. Existem no Brasil trinta pólos de fruticultura, espalhados de norte a sul, que abrangem mais de cinqüenta municípios (EMPRESA BRASILEIRA DE PESQUISA AGROPECUÁRIA, 2005). Em 2004, a fruticultura resultou em uma produção mundial de 675 , I milhões de toneladas, sendo a fruta mais produzida a banana, seguida por melancia e uva. Com a quantidade de 39 milhões de toneladas, o Brasil ocupa o terceiro lugar na classificação dos principais países produtores de frutas, perdendo somente para a produção da China e Índia (TODA FRUTA, 2005).

Em estudo publicado em I999, a Fundação Instituto de Pesquisas Econômicas (Fipe) apresenta a fruticultura como atividade agrícola presente em apenas $5 \%$ das áreas cultivadas no país. No entanto, seu levantamento defende essa atividade como capaz de assegurar ao Brasil um percentual significativo de volume de produção e da sua pauta de exportação. Outra consideração do estudo da Fipe é que, em termos gerais, a demanda por produtos alimentícios de alta qualidade cresceu regularmente nos países desenvolvidos, o que provocou significativo aumento do consumo, principalmente de frutas frescas. Como conseqüência, existe um público habituado a consumir produtos frescos durante todo o ano, seja o produto de origem local seja do exterior. Nesse contexto, o elevado índice de defensivos agrícolas nos produtos frutícolas tropicais tem criado barreiras fitossanitárias para a sua comercialização nos mercados globalizados.

Em suma, o setor de fruticultura, assim como demais setores alimentícios, depara com a crescente necessidade de desenvolver tecnologias, produtos e processos que satisfaçam o mercado no que se refere à qualidade, a custos competitivos, à redução de perdas e segurança alimentar e do alimento. A segurança alimentar relaciona-se fundamentalmente à quantidade de alimentos disponibilizada para a população mundial e à segurança do alimento aos atributos qualitativos dos alimentos, principalmente no que se refere à saúde (SPERS, 2000, p. 284). A segurança do alimento tem sido buscada por meio de ações como rastreabilidade e certificação de produtos, que promovem salvaguardas quanto aos aspectos qualitativos do produto, principalmente fatores fitossanitários. 
Nesse cenário, a citricultura destaca-se por sua importância socioeconômi$\mathrm{ca}$, pois gera centenas de milhares de empregos e movimenta as exportações brasileiras, principalmente no que se refere à exportação de suco de laranja. Até junho de 2005, o Brasil exportou cerca de setecentas toneladas de suco de laranja, via Porto do Santos (ASSOCIAÇÃO BRASILEIRA DOS EXPORTADORES DE CÍTRICOS, 2005). Mesmo assim, ainda existe demanda para a produção de suco e, principalmente, de frutas de mesa.

Em relação ao Estado do Rio Grande do Sul, o agronegócio em geral é um importante segmento da economia, representando $45 \%$ de seu produto interno bruto (PIB) e uma área agricultável de 20,68 milhões de hectares (SECRETARIA DA AGRICULTURA E ABASTECIMENTO..., 2005b). Quanto ao agronegócio da fruticultura no Estado, um levantamento realizado pela Associação Riograndense de Empreendimentos de Assistência Técnica e Extensão Rural - Emater (2004) apontou uma área de pouco mais de I25 mil hectares destinados a pomares comerciais. Nesse levantamento, os cítrus aparecem em segundo lugar no que se refere ao total de área cultivada, perdendo apenas para a produção de uvas, forte da região serrana do Estado. Ao analisarmos separadamente, a laranja e a bergamota ocupam, respectivamente o terceiro e quarto lugares, perdendo para as culturas de uva e maçã.

O Rio Grande do Sul é responsável por apenas 7\% da produção de laranjas e II\% de bergamotas no país. A citricultura nesse Estado é caracterizada pela produção de frutas in natura, o que o torna o melhor do Brasil no que se refere às condições edafoclimáticas para a produção de cítricos de mesa (ASSOCIAÇÃO RIOGRANDENSE DE EMPREENDIMENTOS... , 2002).

O Rio Grande so Sul é o segundo maior produtor de bergamotas do país, e o Vale do Caí se destaca em âmbito estadual, contando, em 2003, com cerca de oito mil hectares cultivados. Os principais municípios produtores são, respectivamente, Montenegro, Pareci Novo, Harmonia, São José do Sul e São Sebastião do Caí (ASSOCIAÇÃO RIOGRANDENSE DE EMPREENDIMENTOS..., 2002).

Quanto à produção de laranjas, no país destaca-se a região Sudoeste, principalmente São Paulo. No Rio Grande do Sul, destacam-se as regiões do Vale do Caí e do Alto Uruguai. O Vale do Caí conta com cerca de quatro mil hectares de pomares comerciais, sendo os principais municípios produtores, respectivamente, São Sebastião do Caí, Harmonia, Tupandi, Pareci Novo e Montenegro (ASSOCIAÇÃO RIOGRANDENSE DE EMPREENDIMENTOS..., 2002).

No geral, a citricultura corresponde a $58 \%$ da produção agrícola da região do Vale do Caí que também concentra 30\% do processamento de carnes de aves e suínas do Estado (SECRETARIA DA COORDENAÇÃO E PLANEJAMENTO DO RIO GRANDE DO SUL, 2005). A região do Vale do Caí totaliza uma área de I.854 km² e contempla os municípios: Alto Feliz, Barão, Bom Princípio, Brochier, 
Capela de Santana, Feliz, Harmonia, Linha Nova, Maratá, Montenegro, Pareci Novo, Salvador do Sul, São José do Hortêncio, São José do Sul, São Pedro da Serra, São Sebastião do Caí, São Vendelino, Tupandi e Vale Real. Como a região do Vale do Caí é principal produtora de bergamotas, optou-se por estudar esse produto nessa região.

\section{A ECOCITRUS}

Como os principais produtores orgânicos da região encontram-se organizados em cooperativa, pretende-se, por meio da descrição do breve histórico desta, buscar elementos que possam contribuir para a análise dos aspectos que caracterizam a racionalidade que move esses produtores a optarem pelo sistema de cultivo orgânico de bergamotas.

O principal objetivo da cooperativa Ecocitrus é desenvolver uma agricultura sustentável, que viabilize a produção do pequeno agricultor sem impactos negativos para o meio ambiente. Para tanto, a cooperativa responsabiliza-se por diversas atividades da cadeia produtiva, como compra de insumos, em alguns casos até mesmo fabricação (biofertilizantes e composto orgânico), contato e fiscalização em parceria com o Instituto Biodinâmico (IBD), processamento das frutas e comercialização. A cooperativa também busca divulgar a proposta agroecológica pela articulação e formação de grupos de agricultores.

A Ecocitrus iniciou suas atividades num contexto caracterizado pelo descontentamento de alguns agricultores com as práticas do modelo convencional (químico), em virtude dos danos causados à saúde do agricultor, do consumidor e do meio ambiente, e por causa da crescente descapitalização do produtor. Paralelamente, na Harmonicitrus, associação de citricultores da região, criada em I990 com o objetivo de comercializar produtos das comunidades da região, cresciam os questionamentos ao modelo convencional e começavam as discussões sobre modelos alternativos.

Outros incentivos vieram com o projeto Prorenda, que viabilizou a formação de jovens da região junto a produtores paulistas, na conversão de seus sistemas produtivos. Com o auxílio e a motivação do Grupo de Cooperação Técnica Alemã e da experiência de alguns associados com agroecologia e compostagem, em I994 é fundada a Associação dos Citricultores Ecológicos do Vale do Caí (Ecocitrus) com quinze produtores, sendo apenas cinco com o processo de conversão dos pomares iniciados.

Segundo França et al. (2002), a Ecocitrus tem investido fortemente na comercialização e industrialização dos produtos dos cooperados, com um trabalho bem maior de pesquisa e extensão agroecológica que envolve parcerias com universidades e órgãos do governo do Estado do Rio Grande do Sul. 
Atualmente, fazem parte da Ecocitrus 43 cooperados, com 64 famílias diretamente envolvidas, totalizando cerca de quinhentos hectares de terras com manejo sustentável. As frutas são comercializadas em supermercados e feiras da localidade, de Porto Alegre, Santa Catarina, Paraná e São Paulo. França et al. (2002) afirmam ainda que o maior problema encontrado para implantação e desenvolvimento da cooperativa foi esclarecer a sua importância para os agricultores e, em particular, a dificuldade de organização das pessoas para participarem de um projeto coletivo, colocando os interesses do grupo acima dos pessoais.

\section{METODOLOGIA}

Neste trabalho, optou-se por uma abordagem essencialmente qualitativa (TRIVIÑOS, I987), com caráter exploratório (GIL, I99I; TRIVIÑOS, I987; VERGARA, I998, p. 45). Exploratória porque há poucos trabalhos que se propõem a estudar de forma comparativa culturas orgânicas e não-orgânicas, ainda mais com relação à citricultura, portanto a pesquisa teve caráter de sondagem. Tratase ainda de um estudo de caso (YIN, 200I), pois estuda um fenômeno contemporâneo dentro da realidade dos citricultores do Vale do Caí. Assim, os sujeitos da pesquisa são os produtores de bergamota orgânica. Os produtores orgânicos foram contatados por meio da cooperativa Ecocitrus, portanto são cooperados. A cooperativa, como intermediadora do contato, foi escolhida de forma intencional por causa de sua história, que apresenta outros valores e motivações que não somente de razão econômica, mas também por sua representatividade no setor de bergamota orgânica da região do Vale do Caí, região representativa no setor de citricultura do Estado e por serem as culturas de laranja e bergamota os principais cítricos cultivados no país e no Estado.

A etapa de levantamento de dados ocorreu em julho e agosto de 2005 e caracterizou-se por duas etapas distintas. Primeiramente, realizou-se aplicação de entrevistas semi-estruturadas com três citricultores orgânicos, com o agrônomo e com o presidente da Cooperativa de Citricultores Ecológicos do Vale do Caí (Ecocitrus), com intuito de identificar fatores relacionados às rotinas e atividades da organização que a identificassem como organização substantiva ou não.

A segunda etapa da coleta de dados ocorreu com questionários fechados aplicados pela pesquisadora no dia da assembléia geral da cooperativa, de forma a atingir o maior número possível de entrevistados, sendo, portanto, a amostra do tipo não-probabilística. Conseguiu-se contemplar vinte produtores dos 43 associados, sendo, dessa forma, a amostra composta por $46,51 \%$ dos cooperados, ou seja, da população que se pretendia atingir. Esse questionário foi estruturado em dois blocos. O primeiro bloco foi constituído de forma a caracterizar o 
produtor e a propriedade onde ocorre o cultivo. O segundo bloco buscou coletar dados relacionados aos elementos que caracterizam a racionalidade substantiva e instrumental, o qual foi composto por questões fechadas com base em escala de Likert de I a 5, desde o "discordo plenamente" até "concordo plenamente". O desenvolvimento das questões e das alternativas propostas no questionário deuse com base nos aspectos levantados nas entrevistas realizadas e no histórico da cooperativa, e inclui questões como o que significa ser produtor rural, cooperado, plantar orgânicos, entre outros aspectos.

Como tratamento dos dados, após caracterização dos sujeitos estudados (cooperados), utilizou-se o construto desenvolvido por Guerreiro Ramos (i989), que classificou os tipos de racionalidade como substantiva e instrumental. Assim, o posicionamento instrumental ou substantivo dos entrevistados foi agrupado, e transferiu-se essa caracterização para a organização, entendendo esta como um reflexo de seus cooperados, que são seus proprietários e gestores. No entanto, para a identificação dos fatores que levam a essa caracterização da organização, utilizou-se a proposta de Serva (I997), que sistematizou os aspectos de cada racionalidade e desenvolveu um continuum da intensidade da racionalidade substantiva. As repostas dos questionários em escala de Likert orientaram a classificação dos aspectos com relação à intensidade da razão substantiva no continuum de Serva (i997).

\section{DISCUSSÃO DOS RESULTADOS: O PRODUTOR ORGÂNICO E A RACIONALIDADE}

\subsection{CARACTERIZAÇÃO DOS PRODUTORES E ANÁLISE DOS RESULTADOS}

A média de idade dos produtores entrevistados ficou em 42 anos, sendo 33 anos a média do tempo como produtor rural, ou seja, a população caracteriza-se predominantemente por pessoas que cresceram e fixaram-se no campo. O tempo de citricultura é de 27 anos em média, e a maioria dos produtores trabalha com a prática orgânica há dez anos, o que coincide com o início das ações que impulsionaram a constituição da cooperativa.

Quanto às propriedades, elas possuem I7 ha em média, no entanto a maioria apresentou uma propriedade de $5 \mathrm{ha}$, sendo a diferença entre a menor e maior propriedade de $37 \mathrm{ha}$, a primeira apresentando $3 \mathrm{ha}$, enquanto a maior é de 40 ha. Essa diferença refletirá na renda média mensal dos produtores que girou em torno de R\$ I.IOO. De acordo com os dados coletados, pode-se ainda inferir que 
a maior parte dos produtores possui outra cultura na sua propriedade (90\%), no entanto a citricultura é tida como a principal atividade e fonte de renda de $80 \%$ dos produtores.

Uma vez caracterizado o perfil do agricultor e de sua propriedade, buscou-se identificar se os produtores estão satisfeitos com sua atual posição. Os produtores pesquisados mostraram-se muito satisfeitos em relação à sua posição de citricultor orgânico, pois obteve-se apenas um resultado negativo, ou seja, apenas um produtor encontra-se muito insatisfeito em ter deixado o sistema de cultivo convencional. Desconsiderou-se essa resposta não apenas porque ela se mostra isolada, mas também porque esse produtor não ratifica sua postura ao ser questionado quanto a ser produtor orgânico, dizendo-se nesse aspecto satisfeito. Corroborando essa análise, tem-se um total de $85 \%$ dos produtores afirmando que não deixariam o campo, dos quais $65 \%$ não fariam isso mesmo que lhes fosse dada a oportunidade de trabalho na cidade. Somam-se a isso $95 \%$ dos entrevistados, nessa questão representando Ioo\% dos respondentes, que afirmaram que o cultivo de produtos orgânicos satisfez, até o momento, suas expectativas.

Quanto à satisfação dos produtores em relação aos resultados de seu trabalho, pode-se inferir que eles estão satisfeitos; apenas dois produtores afirmaram ser indiferentes a essa questão, e um alegou estar insatisfeito com a produtividade e qualidade de seu produto final. Ao serem questionados a respeito dos motivos que influenciaram sua decisão em aderir ao sistema de cultivo orgânico, cerca de $80 \%$ dos produtores afirmaram que isso se deu principalmente por sua iniciativa própria e incentivos de outros produtores. A formação da cooperativa é outro fator determinante para a decisão de $65 \%$ dos respondentes.

Observou-se que diferentes questões pesaram para o produtor decidir quanto ao cultivo de orgânicos. Influenciaram nessa decisão questões que caracterizam um cálculo utilitário de maximização de recursos e retornos (menores custo, melhor retorno, oportunidade de mercado) e aquelas relacionadas a preocupações com o bem-estar do produtor, consumidor e ambiente. Questões como cuidado ambiental, problemas de saúde do produtor e maior qualidade dos produtos tiveram maiores pesos.

Quanto à organização de seu trabalho, 70\% dos respondentes afirmaram ter suas atividades bem planejadas, e $60 \%$ não realizam as mesmas atividades todo o dia. Quanto à divisão do trabalho, $95 \%$ realizam divisão de atividades com outras pessoas. As respostas relacionadas a cooperação e relacionamento com os demais demonstraram uma tendência a uma uma postura do nível racionalidade substantiva, uma vez que $85 \%$ dos produtores afirmaram não ver os demais como concorrentes, mas como colegas ou amigos.

Quanto à cooperativa, cerca de $45 \%$ dos entrevistados a percebem como um simples cliente ou lugar onde a produção é entregue (centro de distribuição). Em 
contrapartida, 95\% dos entrevistados discordam que a cooperativa seja um lugar de conflitos onde preferem pouco participar, pois, para 90\% destes, a cooperativa é lugar de realização pessoal onde podem manifestar suas opiniões.

No geral, pode-se afirmar que os produtores pesquisados estão satisfeitos com sua opção pelo cultivo orgânico e que diferentes fatores os motivaram e ainda motivam a trabalhar com esse sistema de cultivos. Esses fatores serão trabalhados na próxima seção, na tentativa de construir o continuum da intensidade da racionalidade substantiva do grupo pesquisado.

\subsection{DISCUSSÃO ACERCA DA RACIONALIDADE}

O Quadro I, construído por Serva (I997), que resumiu a descrição de alguns processos organizacionais relacionados com os elementos da racionalidade já descritos, é apresentado no Quadro 2 de forma a caracterizar a situação da cooperativa estudada. Assim, o Quadro 2 foi constituído com base nos dados coletados por meio de questionários e entrevistas. A definição do nível de intensidade da racionalidade com relação à organização é dada de acordo com o grau de concordância ou de discordância das respostas na escala Likert do questionário e com base na análise e interpretação dos pesquisadores nas respostas obtidas nas entrevistas realizadas. Quando se analisa o Quadro 2, percebem-se os seguintes aspectos:

- Hierarquia e normas: predominância da racionalidade substantiva, pois hierarquia e normas são discutidas, constituídas e aprovadas pelo grupo nas assembléias mensais. Média presença da racionalidade instrumental, pois a definição delas inclui metas de natureza técnica, econômica, política e sociais, assim como a escolha dos dirigentes inclui análise da performance e das competências individuais dos cooperados escolhidos.

- Valores e objetivos: observou-se nos produtores influência de aspectos relacionados a utilidade, fins e rentabilidade, e também forte intensidade de aspectos relacionados a auto-realização, valores emancipatórios e julgamento ético. Por exemplo, a produção orgânica significa para os produtores alcançar menores custos, maior renda e oportunidade de mercado. No entanto, também significa melhor qualidade de vida do produtor, mais saúde para o produtor e consumidor e autonomia. Esta última ocorre por causa da cooperativa, ou seja, pela independência em relação às transações com terceiros. Em primeiro lugar, os fatores que levaram à predominância da racionalidade substantiva referem-se ao fato de os produtores se apresentarem muito satisfeitos com sua posição atual (auto-realização). Em segundo, apesar de terem preocupações relativas a utilidade, fins e rentabilidade, não se contatou efetivo controle e sistematização de dados para o alcance desses objetivos. 


\section{QUADRO 2}

ANALISE DOS PROCESSOS ORGANIZACIONAIS

E ELEMENTOS DA RACIONALIDADE NOS CITRICULTORES ORGÂNICOS DA REGIÃO DO VALE DO CAÍ

\begin{tabular}{|c|c|c|}
\hline $\begin{array}{c}\text { TIPO DE RACIONALIDADE } \\
\text { VERSUS } \\
\text { PROCESSOS ORGANIZACIONAIS }\end{array}$ & $\begin{array}{l}\text { RACIONALIDADE } \\
\text { SUBSTANTIVA }\end{array}$ & $\begin{array}{l}\text { RACIONALIDADE } \\
\text { INSTRUMENTAL }\end{array}$ \\
\hline Hierarquia e normas & $\begin{array}{c}\text { ELEVADA } \\
\text { Entendimento } \\
\text { e julgamento ético }\end{array}$ & $\begin{array}{c}\text { MÉDIA } \\
\text { Fins e desempenho }\end{array}$ \\
\hline Valores e objetivos & $\begin{array}{c}\text { ELEVADA } \\
\text { Auto-realização, } \\
\text { valores emancipatórios e } \\
\text { julgamento ético }\end{array}$ & $\begin{array}{l}\text { BAIXO } \\
\text { Utilidade e fins }\end{array}$ \\
\hline Tomada de decisão & $\begin{array}{l}\text { ELEVADA } \\
\text { Entendimento e } \\
\text { julgamento ético }\end{array}$ & $\begin{array}{c}\text { MÉDIA } \\
\text { Maximização de recursos }\end{array}$ \\
\hline Controle & $\begin{array}{l}\text { BAIXA } \\
\text { Entendimento }\end{array}$ & $\begin{array}{c}\text { MÉDIA } \\
\text { Maximização de recursos } \\
\text { e desempenho }\end{array}$ \\
\hline Divisão do trabalho & $\begin{array}{c}\text { MÉDIA } \\
\text { Auto-realização, } \\
\text { entendimento e autonomia }\end{array}$ & $\begin{array}{c}\text { ELEVADA } \\
\text { Desempenho e cálculo }\end{array}$ \\
\hline $\begin{array}{c}\text { Comunicação e relações } \\
\text { interpessoais }\end{array}$ & $\begin{array}{c}\text { MÉDIA } \\
\text { Autenticidade, } \\
\text { valores emancipatórios } \\
\text { e autonomia }\end{array}$ & $\begin{array}{c}\text { BAIXA } \\
\text { Desempenho, êxitol } \\
\text { resultados e estratégia } \\
\text { interpessoal }\end{array}$ \\
\hline $\begin{array}{c}\text { Ação social e relações } \\
\text { ambientais }\end{array}$ & $\begin{array}{c}\text { MÉDIA } \\
\text { Valores emancipatórios }\end{array}$ & $\begin{array}{c}\text { MÍNIMA } \\
\text { Fins e êxito/resultados }\end{array}$ \\
\hline $\begin{array}{l}\text { Reflexão sobre } \\
\text { a organização }\end{array}$ & $\begin{array}{c}\text { BAIXA } \\
\text { Julgamento ético }\end{array}$ & $\begin{array}{l}\text { MÉDIA } \\
\text { Desempenho, fins e } \\
\text { rentabilidade }\end{array}$ \\
\hline Satisfação individual & $\begin{array}{c}\text { ELEVADA } \\
\text { Auto-realização e autonomia }\end{array}$ & $\begin{array}{c}\text { MÉDIA } \\
\text { Fins e êxito }\end{array}$ \\
\hline Dimensão simbólica & $\begin{array}{c}\text { ELEVADA } \\
\text { Auto-realização e valores } \\
\text { emancipatórios }\end{array}$ & $\begin{array}{l}\text { MÉDIA } \\
\text { Utilidade e êxito/ } \\
\text { resultados }\end{array}$ \\
\hline
\end{tabular}

Fonte: Adaptado de Serva (I997, p. 24), com a utilização dos dados coletados na pesquisa. 
- Tomada de decisão: na cooperativa, esse processo é feito, na sua maioria, coletivamente, nas assembléias que ocorrem com a periodicidade de uma vez ao mês. Nas questões relativas ao dia-a-dia do produtor na sua propriedade e no cultivo, têm-se as decisões tomadas por ele e, às vezes, auxiliadas pelo agrônomo da cooperativa. O que se identifica é a presença média de elementos que orientam a uma maximização de recursos e utilidade, em questões como utilização de insumos, produtividade, custos e destinação e qualidade dos produtos. E o elemento entendimento, caracterizado pelos acordos e consensos racionais com responsabilidade e satisfação social, é ainda mais forte por causa das condições de comunicação e participação proporcionadas pelas assembléias.

- Controle: caracterizado pela razão instrumental, pois a cooperativa, por meio de parâmetros de utilização de recursos (principalmente insumos) e de desempenho, deve garantir a qualidade dos pomares e das frutas vendidas. Esse controle é fortemente influenciado pela necessidade de manter a certificação (expedida pelo IBD) exigida pelo mercado. Além disso, há uma certa padronização das atividades e das frutas, quando estas se dividem por tamanho e qualidade (apresentação).

- Divisão do trabalho: caracterizada pelo conhecimento dos cooperados a respeito dos processos da cooperativa e por sua participação na decisão relativa a preenchimento de cargos e funções (entendimento). No entanto, essa divisão é definida com base em conhecimento (especialização), competências e resultados apresentados pelos profissionais que fazem parte dos processos da organização.

- Comunicação e relações interpessoais: a racionalidade substantiva revelou-se mais presente (elevada) principalmente na intensidade dos elementos autenticidade e autonomia. Por ser uma organização coletiva, a participação nas assembléias propicia a presença também de valores emancipatórios.

- Ação social e relações ambientais: o cuidado ambiental e a participação em questões políticas e sociais fazem parte das atividades da empresa. A instrumentalidade aqui é percebida mais em questões de êxitos e resultados quanto aos cuidados com o cultivo orgânico.

- Satisfação individual: a satisfação dos membros da cooperativa está relacionada a questões como realização pessoal e autonomia, as quais estão muito interligadas. A realização pessoal se dá em parte pela autonomia que a cooperativa, como empreendimento deles, proporciona e também porque ela auxilia na viabilidade do cultivo.

- Reflexões sobre a organização: as reflexões sobre o andamento da cooperativa, necessidades e problemas, ocorrem na direção e na assembléia, com relativo julgamento ético, no entanto com maior preocupação sobre questões econômicas e de desempenho. 
- Dimensão simbólica: no geral, a cooperativa é vista como um lugar de realização pessoal e autonomia, do qual gostam de participar. No entanto, para alguns também é um simples cliente ou local de entrega da produção, de recebimento dos ganhos.

\section{FIGURA 2}

CONTINUUM DA INTENSIDADE

DA RACIONALIDADE SUBSTANTIVA NA ECOCITRUS

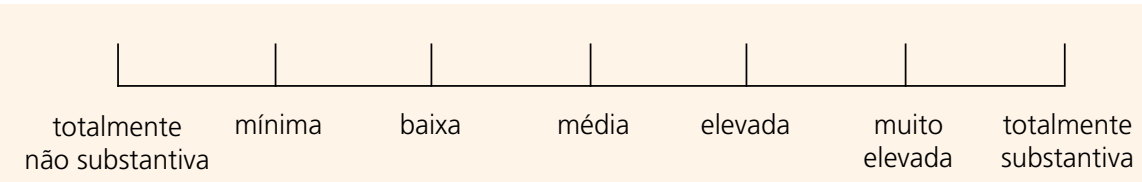

Fonte: Adaptada de Serva (I997, p. 25).

De tal forma, como se apresenta na Figura 2, dos dez elementos analisados (Quadro 2), sete estão guiados muito mais por uma ação racional substantiva do que por uma ação racional instrumental. Considerando que a razão substantiva diz respeito a julgamentos e avaliações com base em preceitos (valores) morais e éticos, e entendendo a organização substantiva de Guerreiro Ramos (I989) como aquela em que esse tipo de razão é predominante, entende-se a Ecocitrus como uma organização substantiva de intensidade elevada, já que seus cooperados têm suas ações, predominantemente, motivadas por razões substantivas.

Indicar a Ecocitrus como substantiva implica entendê-la como uma organização onde: a) se observa o ideal da solidariedade e da emancipação do ser humano, com o propósito de propiciar-lhe autonomia e conhecimento para que se coloque de forma reflexiva e crítica diante das situações vividas por ele e pela organização (desalienação); b) há uma preocupação em atender às diferentes necessidades do ser humano, desde aquelas com caráter econômico até as que envolvem o coletivo (organização e comunidade).

\section{CONSIDERAÇÕES FINAIS}

O objetivo deste estudo de identificar o tipo de razão que predomina nos agricultores orgânicos e na sua organização, e, ainda, de verificar se esse produtor encontra-se satisfeito com sua posição de citricultor orgânico foi alcançado. Constatou-se que os citricultores pesquisados estão muito satisfeitos com sua opção pelo cultivo orgânico e que diferentes fatores os motivaram a aderir a esse 
tipo de cultivo e ainda os motivam. Os principais fatores são: incentivos de colegas, formação da cooperativa, maior cuidado com o meio ambiente e com a saúde do produtor, qualidade do produto e saúde do consumidor, menores custos e melhor retorno.

Também se pôde constatar a predominância da racionalidade substantiva em sete dos dez processos analisados, o que permitiu, com base no continuum construído por Serva (I989), caracterizar a Ecocitrus como uma organização substantiva de intensidade elevada. Contudo, destacam-se alguns resultados referentes à racionalidade instrumental que se mostraram bastante significativos, próximos aos da racionalidade substantiva.

Há algumas ressalvas, como a falta de dados para caracterizar a racionalidade predominante nos conflitos e nas soluções destes. Também se acredita que, para maior confiabilidade dos dados, seriam necessárias mais entrevistas semiestruturadas e maior observação da rotina da organização e, principalmente, das assembléias, em que a presença dos cooperados é maior. Outro aspecto limitador dos resultados obtidos é a sua ligação à análise e interpretação pessoal dos pesquisadores, o que pode influenciar de certa forma os resultados finais.

Como proposta de estudo futuro, vê-se a possibilidade de uma análise da razão que motiva a ação racional dos produtores orgânicos em comparação com a ação racional dos produtores convencionais.

\section{REFERÊNCIAS}

ASSOCIAÇÃO BRASILEIRA DOS EXPORTADORES DE CÍTRICOS (ABECITRUS). Exportações safra 2004/2005. 28 jul. 2005. Disponível em: <http://www.abecitrus.com.br>. Acesso em: 9 out. 2005 .

ASSOCIAÇÃO RIOGRANDENSE DE EMPREENDIMENTOS DE ASSISTÊNCIA TÉCNICA E EXTENSÃO RURAL (EMATER). Estudo da cadeia de citros no Vale do Caí/RS. Porto Alegre: Emater, Ascar, 2002.

Levantamento da fruticultura comercial do Rio Grande do Sul. Porto Alegre: Emater, Ascar, 2004 .

BARNARD, C. I. As funções do executivo. São Paulo: Atlas, I97I. 322 p.

BATALHA, M. O.; SILVA, A. L. da. Gerenciamento de sistemas agroindustriais: definições e correntes metodológicas. In: BATALHA, M. O. Gestão agroindustrial. 2. ed. São Paulo: Atlas, 200I. CEPEA/ESALQ/USP. Disponível em: <http://www.cepea-esalq.usp.br/pib/>.

CORREIA, G. S.; DORNELES, S. B. Uma nova concepção de criatividade na perspectiva da racionalidade. In: ENANPAD, 2003, Atibaia. Anais... Atibaia, 20 a 24 set. 2003.

CZAPSKI, S. Agricultura orgânica conquista o mercado. Botucatu: Instituto Biodinâmico, junho 2005. Disponível em: <http://www.ibd.com.br/artigos/agriculturaecologica.htm>. Acesso em: 5 ago. 2005 . 
DAVIS, J. H., GOLDEBERG, R. A. A concept of agribusiness. Division of research. Boston: Harvard University, I957.

EMPRESA BRASILEIRA DE PESQUISA AGROPECUÁRIA (EMBRAPA). Fruticultura. Disponível em: <http://www.2I.sede.embrapa.br/linhas_de_acao/alimentos/fruticultura/index_html/ mostra_documento>. Acesso em: Io ago. 2005.

FOOD AND AGRICULTURE ORGANIZATION OF THE UNITED NATIONS (FAO). FAO Statistics of Agriculture - FAOSTAT. Disponível em: <http://www.fao.org/waicent/portal/statistics_ en.asp>. Acesso em: 3 ago. 2005 .

FRANÇA, C. L. de; VAZ, J. C.; SILVA, I. P. (Org.). Aspectos econômicos de experiências de desenvolvimento local. São Paulo: Instituto Polis, 2002. 18op. Disponível em: <http://www.unilivre.org.br/ banco_de_dados/experiencias/experiencias/429.html>.

HALWEIL, B. Agricultura ecológica: reduzindo a fome e atingindo metas ambientais. Botucatu: Instituto Biodinâmico, jun. 2002. Disponível em: <http://www.ibd.com.br/artigos/agriculturaecologica.htm>. Acesso em: 5 ago. 2005.

HAWKEN, P.; LOVINS, A.; LOVINS, H. Capitalismo natural: criando a próxima revolução industrial. São Paulo: Cultrix, I999.

KHATOUNIAN, C. A. A reconstrução ecológica da agricultura. Botucatu: Agroecológica, 200I.

KNY, M. A. et al. Análise dos valores pessoais dos produtores de produtos orgânicos. In: XLIII CONGRESSO DA SOCIEDADE BRASILEIRA DE ECONOMIA E SOCIOLOGIA RURAL (SOBER), 2005, Ribeirão Preto. Anais... Ribeirão Preto, 24 a 27 jul. 2005.

MANNHEIM, K. Diagnóstico de nosso tempo. 3 ed. Rio de Janeiro: Zahar, I973. 208 p.

MINISTÉRIO DA AGRICULTURA, PECUÁRIA E ABASTECIMENTO (MAPA). Instrução normativa n. 007 de I7 de maio de I999. Brasília, I999. Disponível em: <http://www.oc4j.agricultura.gov.br/agrolegis/do/consultaLei?op=viewTextual\&codigo=1662>. Acesso em: 8 ago. 2005 .

MINISTÉRIO DO DESENVOLVIMENTO AGRÁRIO. Disponível em: <http://www.mda.gov.br>. Acesso em: 9 ago. 2005.

MORIN, E. Ciência com consciência. 6. ed. Rio de Janeiro: Bertrand, 2002.

PEREIRA, M. J. L. de B.; FONSECA, J. G. M. Faces da decisão: as mudanças de paradigmas e o poder da decisão. São Paulo: Makron Books, I997.

RAMOS, A. G. Administração e contexto brasileiro: esboço de uma teoria geral da administração. 2. ed. Rio de Janeiro: Fundação Getulio Vargas, I983.

A nova ciência das organizações: uma reconceituação da riqueza das nações. 2. ed. Rio de Janeiro: Fundação Getulio Vargas, I989.

SACHS, I. Brasil rural: da redescoberta à invenção. Estudos Avançados, São Paulo, USP, n. 43, set./ dez. 2001.

SACHS, I. Caminhos para o desenvolvimento sustentável. Rio de Janeiro: Garamond, 2002.

SECRETARIA DA AGRICULTURA E ABASTECIMENTO DO RIO GRANDE DO SUL (SAA). Indicadores agropecuários. Disponível em: <http://www.saa.rs.gov.br/>. Acesso em: 7 ago. 2005 .

Programa Estadual de Fruticultura - Profruta. Disponível em: <http://www.saa.rs.gov. br/>. Acesso em: 7 ago. 2005b.

SECRETARIA DA COORDENAÇÃO E PLANEJAMENTO DO RIO GRANDE DO SUL (SCP). Rumos 2015: estudo sobre desenvolvimento regional e logística do estado. Porto Alegre: SCP, maio 2005 . 
SERVA, M. O fenômeno das organizações substantivas. Revista de Administração de Empresas, São Paulo, v. 33, n. 2, p. 36-43, I993.

. A racionalidade substantiva demonstrada na prática administrativa. Revista de Administração de Empresas, São Paulo, v. 37, n. 2, p. I8-30, abr./jun. I997.

SIMON, H. Administrative behavior. New York: Free Press, I997.

SPERS, E. E. Qualidade e segurança em alimentos. ZYLBERSZTAJN, D.; NEVES, M. F. Economia e gestão dos negócios agroalimentares: indústria de alimentos, indústria de insumos, produção agropecuária, distribuição. São Paulo: Pioneira, 2000.

TODA FRUTA. Principais países e quantidades de frutas produzidas no mundo. 26 jul. 2005 . Disponível em: <http://www.todafruta.com.br>. Acesso em: 7 ago. 2005.

TRIVIÑOS, A. N. S. Introdução à pesquisa em ciências sociais: a pesquisa qualitativa em educação: o positivismo, a fenomenologia, o marxismo. São Paulo: Atlas, I987. I75 p.

VERGARA, S. C. Projetos e relatórios de pesquisa em administração. 8. ed. São Paulo: Atlas, I998. $96 \mathrm{p}$.

WEBER, M. Economia e sociedade: fundamentos da sociologia compreensiva. Brasília: Ed. da Unb, 2004 .

YIN, R. K. Estudo de caso: planejamento e métodos. 3 ed. Porto Alegre: Bookman, 2005. 2I2 p. ZYLBERSZTAJN, D. Conceitos gerais, evolução e apresentação do sistema agroindustrial. In: ZYLBERSZTAJN, D.; NEVES, M. F. Economia e gestão dos negócios agroalimentares: indústria de alimentos, indústria de insumos, produção agropecuária, distribuição. São Paulo: Pioneira, 2000 .

TRAMITAÇ ÃO

Recebido em 6/11/2006

Aprovado em 27/1/2007 